\section{Summary Of The Study Of Non-Interpretations}

\author{
Siddikova Shoxida Isokovna
}

Doctor Of Philosophy In Philology (Phd), Department Of

Theory And Practice Of Primary Education, Jizzakh State

Pedagogical Institute, Jizzakh, Uzbekistan

\begin{abstract}
G OPEN ACCESS
The American Journal of Social Science And Education Innovations JULY 2020

Page No.: 366-370

Volume-II Issue-VII

PUBLISHED: 31 JULY 2020 www.usajournalshub.com/inde x.php/tajssei

Copyright: Original content from this work may be used under the terms of the Creative Commons Attribution 4.0 licence.
\end{abstract}

\title{
Abstract
}

This article discusses the study of non-native quotations, issues of research by linguists, views on linguistic features and their artistic specificity. At the same time, there are some comments that the formation of the structure of non-proprietary sentences is based on the laws of the text, not on the grammar.

Keywords: non-personal excerpts, literary text, external non-excerpts, internal nonexcerpts, speech activity

\section{Introduction}

In Uzbek linguistics, the study of non-native quotations is associated with the name of linguist M. Askarova. The scholar points out that these statements are mainly used in works of art: "Non-personal excerpts are more common in works of art. In this case, the author speaks in the language of the character or expresses his reaction to the event "[1].

"In works of art, the author actually speaks, but in his point of view, the character's thoughts, inner speech, thoughts are reflected. An idea expressed through a nonproprietary statement is accepted as both the author's statement and the character's statement "[2]. 


\section{Materials and methods}

A linguist who has specifically studied the constructions of speech in the Uzbek language, A. Abdullayev divides them into several types, and in linguistics he calls non-native transcripts "bilateral consonant constructions." "Bilateral consonant constructions are one of the forms of expression of other consonants and are mainly used in fiction. Although bilateral pronouns are similar in form to quotations, they are distinguished by the fact that they are expressed by the writer in their own words, often without a separate author's pronoun. "[3] Linguists B. Yuldashev, S.Isroilov the role of non-personal excerpts in the literary text, Isroilov notes: it also affects the ability to use forms of speech. The incorporation of non-proprietary forms of speech into the narrative structure of the work reflects the artist's worldview, aesthetic views, spiritual image and personality "[4].

\section{Result and discussion}

The Explanatory Dictionary of Linguistic Terms defines an excerpt that is not its own as follows: "An excerpt in which the author participates as a speaker in an excerpt. In this case, the author speaks in the language of the character or makes his own comment on the story. "[5] In addition to the syntactic units that are actively used in the expression of ideas in a literary text, non-personal excerpts also serve to create an image, character and image. allows artistic-aesthetic depiction accordingly. "The aesthetic task facilitates the main communicative function of language, enriches its possibilities. Language and speech, with the same aesthetic function, express expressiveness, the power of influence "[6].

Speech activity is a unique manifestation of national-spiritual culture, because in every nation, the expression of ideas on the basis of centuries-old norms of speech culture is a delicate art. Language fully expresses its social functions in the process of communication. It is not only a means of communication, expression and transmission, influence, but also a means of collecting and storing spiritual knowledge of the conceptual worldview, of perceiving objective reality. Man possesses not only the language to which he belongs, but also an individual way of perceiving a certain national-cultural mentality and reality. Language also reflects the mental, inner world, mental level, linguistic personality of a person. Therefore, in recent years, the focus on the study of the role of language units in the anthropocentric direction in the expression of human-world relations, the psyche of the linguistic person, thoughts, dreams and hopes has increased significantly. Indeed, for modern linguistics, the human factor and, in particular, the issue of a particular "linguistic personality" are important as objects of scientific analysis [7].

The human factor plays an important role in speech activity. It is a key figure in controlling mechanisms such as planning, realizing, and implementing the strategy of a speech movement. In the system-structural paradigm there is a "human factor" is the main figure. In the system-structural paradigm, the concept of 'human factor' is recognized in relation to 'the ideal speaker in the same speech context' and is interpreted by the definition of 'linguistic ability'. In the pragmatic linguistic paradigm, however, the concept of the "human factor" takes on a completely different meaning. Sh.Safarov divides these types of social characteristics into stable (permanent) and variable groups, and concludes that the personal and social characteristics of the speaker are more important for pragmalinguistic analysis than the concept of "ideal speaker - speaker" [8]. 
An analysis of the traditional and Western literature on linguistics shows that there are three approaches to the study of text, the grammatical, semantic, and pragmatic, which are mutually compatible with the research criteria. The basic unit of text structure is a piece of speech that is spiritually, communicatively, and structurally complete.

The issue of non-proprietary speech, which arose in the 19th century, has become a controversial issue from a terminological point of view. Each researcher tried to name and interpret it on their own. At the beginning of the last century, the term "non-own excerpt" was coined in traditional science. But its entry into circulation as a term in traditional linguistics has led associated with the name V.N.Voloshinov. It was he who reviewed and analyzed all the theories proposed in 1929, distinguished the main descriptions of the phenomenon, collected views on the linguistic features of the non-native quote, and determined its artistic specificity.

The formation of the structure of non-own excerpts according to the laws of the text, not according to the grammar, takes place in the artistic text through the thinking, the consciousness of the creator. As a generalization of the author's thoughts, the text demonstrates this both at the semantic level and at the grammatical level.

Compositional speech construction can include author's speech, excerpt, non-his own speech. Their normative description is as follows: the author's speech is in a monologue and appears in the first and third person forms. In the first person form the author emphasizes the "I" and is expressed in the explicit form, and in the third person form the author is not expressed in the explicit form. The author's speech occupies a significant place in the artistic prose text, performing the functions of describing, narrating, reflecting on the object of speech. The author is based on the existing norms of literary language in the expression of speech. In the excerpt, the character of the literary text appears as the subject of the speech - the sender and the person to whom the speech is addressed - the recipient. The author of the work, of course, has a certain communicative purpose in the use of each linguistic unit. Accordingly, the main function of quotations in the literary text is to describe the heroes of the work, to create a perfect portrait of them. The level of use of quotations in literary texts is significantly lower than that of the author. In an internal monologue, the speaker is both the person to whom the speech is directed and the person. The functional adaptation of the inner monologue is the disclosure of the inner world of the subject of speech, his inner experiences, feelings, attitude to the facts of reality and their evaluation. Traditionally, the use and significance of an internal monologue is determined by the subject. In this case, non-personal excerpts serve to acquaint the reader with the subject - the linguistic person.

Non-possessive clauses formed within the composition-speech structure were formed later than clauses and assimilation clauses. In the communicative context, the description of the linguistic person plays an important role in the author's speech, while the message conveys the content of the information.

An excerpt that is not an external one includes such topics as a subject sentence, a hidden sentence, an adverbial sentence, an in-sentence sentence, and a collective sentence. The oral presentation of the character's speech unites them all at one point. This ensures that their brevity, conciseness, is immediately apparent after the non-original excerpt inserted into the text by the author.

Non-proprietary quotations appear in literary texts in the form of non-proprietary 
internal speech. It interconnects inner reflection, inner monologue, and flow of thought. Unlike external speech, non-proprietary speech on the basis of internal non-proprietary speech lies in non-proprietary speech. We understand non-internal speech as an internal excerpt that is expressed in a plot line given in the author's description field, based on reality and free from introductory words and rotations. Non-possessive pronouns are characterized by the expansion of their structure, syntactic complexity, and the ability to perform certain pragmatic tasks.

The similarity of the functions of the non-native excerpt and the internal monologue in the literary texts often leads to considering them as the same, and we define their criteria on this basis. Taste that the inner speech in the literary text will be well understood by the reader.

\section{Conclusion}

Internal speech in a literary text requires reworking by the author to ensure that it is well understood by the reader. In artistic similarity, inner speech distinguishes the flow of thoughts, the inner monologue, the inner speech in between, the audiologies. The classification is based on the criteria and size of the breakdown. The flow of ideas is sparsely distributed and abundant. It is also difficult for the reader to perceive what they are reading according to the weakness of their inner connection. In every way, the inner speech expresses the inner world of the protagonist - his feelings, thoughts, outer sorrows. It is an integral part of character speech. But it differs from the external expression in form, in its structure, and in the absence of graphic punctuation in the text. This serves as evidence that some researchers view internal speech and non-native excerpts as the same.

But a comparative analysis of these two aspects of speech (including the internal monologue as an internal speech view) shows that there is a stark difference between them. What has become clear is that a non-native excerpt and an internal monologue interact differently when narrating in the same plot line. The non-specific excerpt used in literary texts stands alongside the author's speech as a plot-developing component of the whole text. On this basis, we can also say that it includes elements of logical and emotional perception of evidence. Unlike an internal monologue, an excerpt that is not its own does not constitute a plot movement, but is an integral part of it.

The inner monologue stops the plot movement. The character thinks to go back to the time elapsed before the accident, and the action expressed in the text ceases.

The inner monologue evokes strong emotions in the reader. The character's inner monologue participates as the primary means of conveying information about his or her inner experiences. As the protagonist reflects on the events taking place in society, he seeks to define his place in the series of events and his attitude to them.

Second, morphologically there is linguistic divergence, i.e., differences. The internal monologue is given to the moving person in the form of introductory words and phrases that transform grammatical tense forms, identity and possessive pronouns into a singular form.

In a non-possessive copy, the word is not given to the person moving - this is a characteristic of this type of speech. In it, the author's language encompasses the character's speech and thinking while preserving the morphological features of the 
author's narrative. Naturally, the 3 person singular form of the pronouns of identity and possession remains unchanged.

Thus, the internal monologue and the non-own excerpt are different linguistic phenomena.

\section{References}

1. Gulomov A., Askarova M. A. Modern Uzbek language. Syntax. T., 1961. 265-266p.

2.Saidniyozov A. "In other words, the role of Russian linguists in its study." $\mathrm{T}$.: 1983. p.35.

3.Abdullaev A. Extractive constructions in modern Uzbek literary language. $\mathrm{T}$.: "Fan", p.13.

4.Yuldashev B, Isroilov O. "Grammatical and stylistic features of non-native excerpts and their place in the literary text." Samarkand, 1991, P.26.

5. Hojiev A. Explanatory dictionary of linguistic terms. Tashkent: Teacher, 1985. 115 pages.

6.Mahmudov N. Speech culture and the aesthetic function of language // Philological issues.2006, № 2 (11). Page 51

7.Pardaev Z. Pragmatic linguistics. Methodical manual. -Samarkand, 2013. p.72.

8.Safarov Sh. Pragmalinguistics.-Tashkent: National Encyclopedia of Uzbekistan, 2008. -P.153. 